\title{
Early-Stage Breast Carcinoma
}

National Cancer Institute

\section{Source}

National Cancer Institute. Early-Stage Breast Carcinoma. NCI Thesaurus. Code C94774.

Breast carcinoma that has not spread beyond the breast and the axillary lymph nodes. 